\title{
Síndrome de la cimitarra y disnea en una paciente de 87 años
}

\author{
Right paracardiac linear opacity in an elderly woman
}

Mujer de 87 años sin antecedentes de interés excepto enfermedad renal crónica. Ingresa por disnea. La radiografía de tórax mostraba una opacidad lineal paracardiaca derecha (figura 1, flecha) correspondiente a una estructura vascular (signo de la cimitarra) e hipoplasia del pulmón derecho. Se realizó una angio-TC torácica que ponía de manifiesto la existencia de defectos de repleción en ramas subsegmentarias de lóbulos superior derecho e inferior izquierdo en relación con tromboembolismo pulmonar y un drenaje venoso anómalo de las venas de los lóbulos medio e inferior derechos a la vena cava inferior (figura 2, flecha). No se observó agenesia de arteria pulmonar en la TC o comunicación interauricular en un ecocardiograma transesofágico. Fue tratada con anticoagulación y no se planteó cirugía correctora de la malformación por la escasa expresividad clínica del cortocircuito. En los meses siguientes no presentó ninguna complicación adicional.

El drenaje venoso pulmonar anómalo es una entidad congénita poco frecuente, en la que existe una malformación de una vena pulmonar, generalmente derecha, que drena en el corazón derecho o en el sistema venoso sistémico, en lugar de hacerlo en la aurícula izquierda ${ }^{1,2}$. En ocasiones este trayecto venoso anormal se observa como una imagen lineal paralela al borde derecho del corazón, que se denomina signo de la cimitarra por su forma que recuerda a la de la espada del mismo nombre. Pueda asociarse a hipoplasia del pulmón derecho y de la arteria pulmonar derecha, dextrocardia, anomalías traqueobronquiales, irrigación anómala de la aorta al pulmón derecho (secuestro pulmonar) y, más raramente, malformaciones cardíacas como comunicación interauricular, tetralogía de Fallot coartación aórtica o persistencia del conducto arterioso $0^{3,4}$. Existen dos formas clínicas: la forma infantil que se caracteriza por una mayor frecuencia y gravedad de los defectos mencionados, es sintomática desde edades muy tempranas y requiere corrección quirúrgica. Por el contrario, la forma adulta se asocia con menos frecuencia a otras anomalías, cursa de forma asintomática o con muy escasa expresividad clínica y no suele requerir tratamiento específico ${ }^{3}$. El diagnóstico de la forma adulta suele realizarse en la adolescencia o en los primeros años de la vida adulta; el diagnóstico en ancianos, como el caso que presentamos, es excepcional.

\section{Bibliografía}

1. Espinola-Zavaleta N, Játiva-Chávez S, Muñoz-Castellanos L, Zamora-González C. Aspectos clínicos y ecocardiográficos del síndrome de la cimitarra. Rev Esp Cardiol 2006; 59: 284-8.

2. Frydrychowicz $A$, Landgraf $B$, Wieben 0 , François CJ. Scimitar syndrome: added value by isotropic flow-sensitive four-dimensional magnetic resonance imaging with PC-VIPR (phase-contrast vastly undersampled isotropic projection reconstruction). Circulation 2010; 121: e434-6.

3. Dusenbery SM, Geva T, Seale A, Valente AM, Zhou J, Sena L, et al. Outcome predictors and implications for management of scimitar syndrome. Am Heart J 2013; 165: 770-7.

4. Nazarian J, Kanne JP, Rajiah P. Scimitar sign. J Thorac Imaging 2013; 28: W61.

\section{Diagnóstico: Drenaje venoso pulmonar anómalo. Signo de la cimitarra.}

\author{
Alfonso Gutiérrez Macías ${ }^{1}$, Silvia Cisneros Carpio ${ }^{2}$ \\ Servicios de Medicina Interna ${ }^{1}$ y Radiodiagnóstico ${ }^{2}$ \\ Hospital Universitario Basurto. Bilbao.
}

Correspondencia: alguma6725@outlook.es

Como citar este artículo: Gutiérrez Macías A., Cisneros $S$.

Sindrome de la cimitarra y disnea en una paciente de 87 años. Galicia Clin 2016; 77 (1): 44

Recibido: 01/11/2015; Aceptado: 17/11/2015

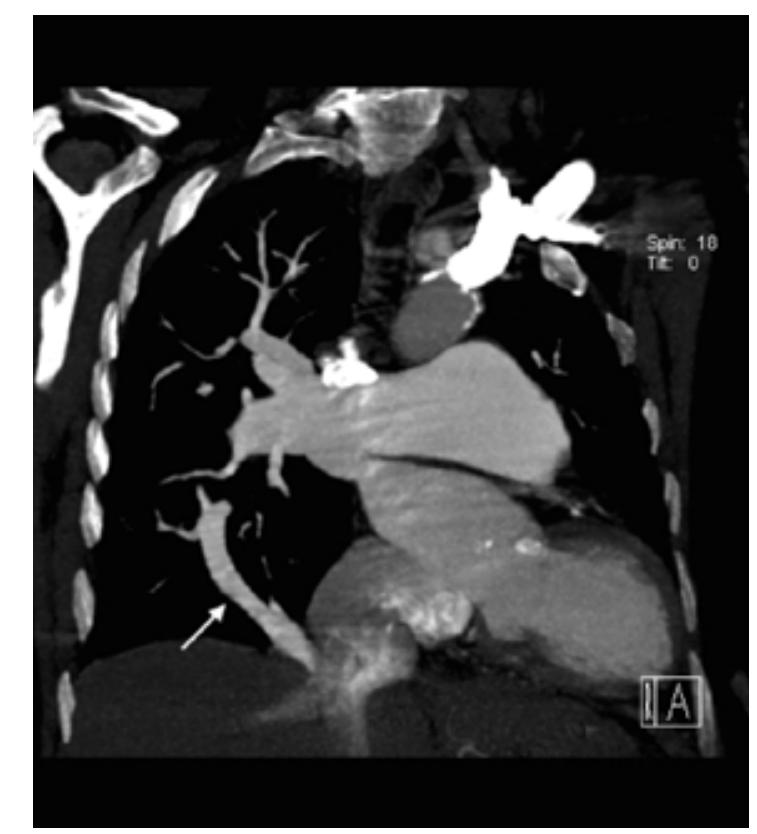

